\title{
The Process of Janusian Thinking in Creativity
}

\section{Citation}

Rothenberg, Albert. 1971. “The Process of Janusian Thinking in Creativity." Archives of General Psychiatry 24 (3) (March 1): 195. doi:10.1001/archpsyc.1971.01750090001001.

\section{Published Version}

doi:10.1001/archpsyc.1971.01750090001001

\section{Permanent link}

http://nrs.harvard.edu/urn-3:HUL.InstRepos:30203400

\section{Terms of Use}

This article was downloaded from Harvard University's DASH repository, and is made available under the terms and conditions applicable to Other Posted Material, as set forth at http:// nrs.harvard.edu/urn-3:HUL.InstRepos:dash.current.terms-of-use\#LAA

\section{Share Your Story}

The Harvard community has made this article openly available.

Please share how this access benefits you. Submit a story.

\section{Accessibility}


"Janusian thinking"--the capacity to conceive and utilize two or more opposite or contradictory ideas, concepts, or images simultaneously-is discussed in relation to its role in the creative process in art, literature, architecture, music, science, and mathematics. I feel that understanding the psychological factors in creativity should be of importance in the theory and everyday practice of the art of psychotherapy.

$P$ ETS, philosophers, and theologians have long been concerned with the nature and meaning of creativity in human experience. The scientific study of creativity began largely with the biologically oriented investigations of genius by Lombroso $^{1}$ and Galton ${ }^{2}$ in the late 19 th century. Both of these studies were based on long-standing assumptions: Galton tried to establish that genius was an inherited capacity and Lombroso tried to establish a link between genius and pathological disturbance. Neither study proved its assertions about genius nor, by implication, any assertions about creativity. Furthermore, these investigations generated little scientific interest in the problem of creativity and produced few followers. The real upsurge of interest in creativity began with the advent of psychoanalysis in the early part of this century. Freud himself was a highly cultured man, living in the artistically rich milieu of turn-ofthe-century Vienna, and he turned to great works of art and biographies of great artists to find corroboration of his theories about the nature of man. Although he specifically disclaimed that his forays

Accepted for publication July 8, 1970.

From the Department of Psychiatry, Yale University School of Medicine, New Haven, Conn.

Reprint requests to Department of Psychiatry, Yale University School of Medicine, 333 Cedar St, New Haven, Conn 06510. into art were studies of creativity, ${ }^{3}$ many of his followers could not resist speculating about the richly suggestive biographical and artistic material they analyzed. Since great artists were clearly creative individuals, the early analysts assumed that analysis of artists' life histories in relation to characters and themes in the artists' completed works would inevitably shed direct light on the creative process. Although this type of approach to creativity is fraught with basic conceptual pitfalls, as I have tried to show extensively elsewhere, ${ }^{4}$ these early forays into art produced many psychodynamic formulations about creativity which still have a degree of creditability in psychoanalytic circles. In recent years, analysts have changed their approach somewhat and attempted to combine analyses of artists' biographies and of great works of art with material derived from their own clinical work with gifted patients. In some cases, earlier formulations about creativity were reiterated with slight modification and, in others, new formulations were presented. Examples of the more prominent psychoanalytic formulations about the motive and capacity for creativity are the following: jealousy of female procreation, ${ }^{5}$ mobile depression, ${ }^{6}$ heightened oedipal conflicts, ${ }^{7}$ expansion of ego boundaries, ${ }^{8}$ and extended interest in the transitional object in childhood.9 By far the most famous and most widely held psychoanalytic hypothesis about creativity is the "regression in the service of the ego" notion of Ernst Kris. ${ }^{10}$ Kris developed his notion from wide familiarity with art biography, art history, and aesthetic theory as well as clinical observations. Like other psychoanalytic formulations about creativity, "regression in the service of the ego" is highly general and somewhat vague but it sharply distinguishes creative states from pathological states such as psychosis. Further- 
more, it attempts to account for the artist's apparent capacity to include unconscious, ordinarily repressed material, in great works of art. Historically, Kris's work on creativity represented a divergence of interest from the earlier psychoanalytic studies on art. Whereas the earlier works were primarily focused on universal psychodynamic processes exemplified in the lives of artists and in great works of art and were only incidentally (albeit forcefully) concerned with creativity per se, Kris focused directly on creativity as part of his general interest in clarification and development of ego theory. Along with Anna Freud, Heinz Hartmann, and Rudolph Loewenstein, Kris contributed to a new psychoanalytic emphasis on ego functioning, an emphasis that persists to the present day.

Approximately 20 years ago, psychologists of diverse theoretical backgrounds became interested in creativity partly because of a resurgence of interest in ego function pervading the field of psychology at the time. Returning from a notable preoccupation with motives, emotions, and psychopathology to their traditional concern with ego functions such as perception and cognition, psychologists began to apply newly achieved experimental methodologies and computer technology to the problem of creative thinking as a special type of cognitive process. Creativity research in psychology and other fields received further impetus in this country at the beginning of the last decade when an apparent lag in space technology raised widespread concern about traditional American superiority in scientific achievement. Research on scientific creativity and artistic creativity as well was strongly encouraged at that time in the hope that such research would help boost America's seemingly sagging potential. Interest in developing creativity swept the field of education particularly and today the word "creativity" has become a byword on almost every new curriculum or teaching proposal. Results of diverse types of psychological studies in creativity and impressionistic evaluations of educational programs designed to enhance creativity have so far consisted of delineation of general traits or faculties such as: verbal fluency, ideational fluency, redefinition, elaboration and evaluation factors, and originality ${ }^{11}$; courage, femininity in male subjects, perceptiveness and openness to experience, and independence of thought and actions ${ }^{12}$; capacity to bring together remote associations ${ }^{13}$; capacity to defer judgment and extend effort in idea production. ${ }^{14}$

In psychiatry, attempts to study creativity continue to have pertinence as explorations of ego functioning. In spite of the apparently high incidence of psychopathological disturbance among creative people, the process of creating seems to be a highly adaptive function. Erikson, for one, has asserted that an important but neglected form of ego adaptation is the capacity to change the environment. ${ }^{15}$ Since adaptation is a critical aspect of so-called normal functioning, explorations in creativity potentially contribute to an understanding of normality as well as psychopathological abnormality.

It is self-evident that better delineation of adaptation and normality would be directly pertinent to the theory and practice of psychiatric therapy. One further issue bears mentioning, however. Psychotherapy, a major modality of psychiatric treatment, is clearly more an art than it is a science at the current stage of our knowledge. Although interest in creativity began with poets, philosophers, and theologians, it now seems crucially important for psychiatrists to understand and delineate the psychological factors in creativity, particularly artistic creativity, since such understanding should have direct application to the basic theory and everyday practice of psychotherapy in all its forms.

\section{The Definition of Creativity}

A difficult problem besetting all scientific research in creativity pertains to the essential definition of the phenomenon itself. Creativity is not synonymous with originality, productivity, spontaneity, good problem-solving, or craftsmanship although the term is often used interchangeably with all of these. Creations are products which are both new and valuable and creativity is the capacity or state which brings forth creations. A painter may be original but uncreative; a literary scholar may be productive, even prolific, but notably uncreative; a spontaneous person may produce conventional poems spontaneously; computers as well as scientists provide good but uncreative solutions to problems; and the skilled craftsman may replicate great works of art over and over again but never be able to create one of his own. Many scientific explorations into creativity have ignored or shown confusion about these distinctions and much laborious and meticulous research has yielded results which have little if any direct pertinence to the phenomenon. But the basic problem lies deeper than that even if we restrict the definition of creations to products which are both new and valuable, it is difficult for a scientific psychology to attempt to explain the appearance of such products; it is difficult, if not impossible, to explain the act of creation. Value judgments are anathema to objective scientists and the value judgment that designates a new product as true creation is subject to extensive variation depending on time, place, and person. Even more difficult for the scientist, particularly the determinist scientist, is the criterial attribute of newness or novelty. As Hausman ${ }^{16}$ and Morgan ${ }^{17}$ have pointed out, if the concept of novelty in creation is taken literally, ie, a creation is truly 
new and therefore radically different from its antecedents, it is impossible to account for all the factors leading to its production and it is impossible to predict what it will be before it actually appears. I will return to this problem again later. At this point, I would simply like to make clear that I am going to define a previously undescribed thought process operating in the act of creation, a process which accounts for a limited aspect of creativity although it by no means explains the phenomenon. In defining this process, I will assume that creations are products which appear new and are considered valuable by consensus, ie, experts have considered them creations over extended periods of time.

The thought process I will describe is based in part on the notion of structural opposition. Although Jung has emphasized the importance of opposition in all of psychic life ${ }^{18}$ and philosophers, poets, and critics have, at various times, recognized the importance of opposition in works of art, the thought process I will describe pertains specifically to the act of creation. It does not, like Jung's opposition principle, necessarily pervade the psychic life of everyone or the entire psychic life of the creative person, but functions particularly when the creative person is engaged in creating. Furthermore, it involves simultaneity of opposition. Although opposition is often present in a completed work of art, a point I will soon corroborate, it has not previously been suggested that a specific thought process involving simultaneity of opposition could account for its presence.

\section{Janusian Thinking}

I call this process "Janusian thinking." I first described or discovered this thought mechanism several years ago in connection with an intensive study of the revision process in Eugene O'Neill's play,
The Iceman Cometh.4 At that time I called the process "oppositional thinking"- - the capacity to conceive and utilize two or more opposite or contradictory ideas, concepts, or images simultaneously. I have substituted the term "Janusian" for "oppositional" because it more accurately conveys the simultaneity of opposition and because, as a metaphor, it embodies the process it denotes. Janus, of course, was the Roman god with two faces, the god who looked and apprehended in opposite directions simultaneously. He was the god of all doorways and his two faces (Janus bifrons) allowed him to observe both the exterior and interior of a house and the entrance and exit of all buildings. It is perhaps not generally known that he was a very important god, appearing at the head of religious ceremonies and, on the Roman list, he came even before Jupiter. He was the god of "beginnings," presiding over daybreak, and was considered to be the promoter of all initiative. His role as beginner is commemorated in the name January, the month which begins our year. In fact, he had an essential role in the creation of the world itself and was also known as Janus Pater, the god of gods. Of particular interest for this exposition of Janusian thinking,.especially in relation to artistic creation, is the fact that Janus was also considered to be the god of all communication, an extension of his function as god of departure and return.

In the original exposition of the thought process, I presented evidence (derived from extensive study of revisions in the play, life history information, and extensive interviews with O'Neill's widow, Mrs. Carlotta Monterrey O'Neill) that the central iceman symbol in the play The Iceman Cometh had at least three different connotations: (1) the iceman was death (this is stipulated in the play itself); (2) the iceman was Christ (the phrase "the iceman cometh" refers to the biblical phrase "the bridegroom cometh" and the play is structured as a modern parable of the Last Supper); and (3) the iceman was a sexually potent adulterer (based on an old joke known to O'Neill which goes as follows: a husband comes home from work and calls upstairs, "Dear, has the iceman come yet?" His wife calls back down, "No, but he's breathing hard!"). Substituting these meanings into the central creation of the play, the notion of the iceman coming, produces four or more logically opposite ideas: (1) Christ's coming or deliverance is the opposite of bleak death; (2) sexual potency is the biological and, according to Freud and others, the psychological antithesis of death; (3) a bridegroom and an adulterer are polar extremes; and (4) infidelity is opposed to the ultimate tenet of Christian faithfulness, Christ's coming. A potential fifth and probably more implicit opposition is the celebration and elevation of sexuality, particularly illicit sexuality, in conjunction with Christ himself. Christ was not only the opponent of illicit sex, especially adultery, but his teaching could be considered to be generally antisexual or antihedonistic. In the unconscious, of course, many of these oppositions can be significantly equivalent and one of the sources of the awful strength and beauty of the iceman symbol is its ability to connote logical contradiction and basic truth simultaneously - in other words, the integration of opposites.

In this same study, I also presented evidence that suggested that $O$ 'Neill arrived at a central idea in the play, an idea which led in part to his creation of the iceman symbol, by means of a simultaneous conceptualization of opposites. This idea pertained to the suicide of the man who was O'Neill's roommate during the year 1912, a man upon whom the 1939 play was based in large part and who was represented in the play be a character named "Jimmy Tomorrow." O'Neill came 
to realize that this roommate committed suicide because, as the man had said, he was upset about his wife's infidelity with another man, but also because of an opposite feeling - he had unwittingly wanted his wife to be unfaithful to him. All his life, O'Neill had been plagued by the memory of this man's suicide and plagued by the man's assertion shortly before he died that his wife's infidelity had brought him to his state of deep depression. It appears that only in his later life did O'Neill come to realize that the man had also wanted his wife to be unfaithful and that this was a motivating factor in the suicide. This insight was incorporated into The Iceman Cometh and the evidence indicates that it had a good deal of influence on the structure of the play and O'Neill's motivation to write it.

As exemplified in O'Neill's creation of The Iceman Cometh, Janusian thinking is a type of thought process used by a creator while engaged in a creative act. It primarily occurs early in the creative process, the so-called inspiration phase (eg, O'Neill's discovery early in the conception of The Iceman Cometh play that his roommate both wanted and did not want his wife to be unfaithful) and is often, therefore, frequently hidden although its effects may be manifest in the final product, ie, the simultaneous oppositions in the iceman symbol. Janusian thinking may enter into basic plot ideas, specific early metaphors, or early formulations of the overall structure of a work of art; it may not be apparent or remembered by the artist himself and it may or may not lead to clear oppositions in the completed work. Moreover, within the psychoanalytic model of thought, the process of Janusian thinking must be considered to be a secondary process mechanism. The evidence indicates that $O^{\prime}$ Neill arrived at these insights by a simultaneous conceptualization of opposites on a conscious ego level. He was completely aware of the contradiction in his roommate's simultaneous wishes for fidelity and infidelity and he must have been aware of some if not all of the contradictions embodied in the symbol of the iceman in the play. Furthermore, he did not unearth his own unconscious by slavishly employing the freudian formula that unconscious motivations are often opposite conscious ones, nor did he engage in any process of making his own unconscious conscious. There is evidence that he did not apply the insight about his roommate, for example, to his own thoughts about infidelity and that the notions remained embedded as emotionally isolated issues in the play itself. In fact, one of the general characteristics of such creative insights is that an author often actually denies that they have any relation to his own feelings or conflicts. They are considered to be relevant only to the work of art; a common assertion of novelists and playwrights is that such ideas are only insights into the feelings, thoughts, and conflicts of the characters in the work itself.

It is important to stress the secondary process nature of Janusian thinking because primary process thinking has previously been considered to be a crucial aspect of the creative process. As a secondary process mechanism, however, Janusian thinking helps account for the seeming ubiquity of primary process thought in works of art. As mentioned earlier, Kris and others had long been interested in the apparent ability of the artist to render unconscious material manifest in art. Since the artist, unlike the schizophrenic, does not seem to be overwhelmed by primary-processlike thinking, Kris postulated his concept, "regression in the service of the ego," to emphasize the phenomenon of ego control. At the time he presented this concept, Kris quoted Freud's comment that "one would like to know more about how, precisely, the ego achieves this."19
One important aspect of the concept of Janusian thinking is that it offers a partial answer to this question in that it describes a specific ego process which allows primaryprocess-like material to appear in consciousness. This form of thinking, the simultaneous conceptualization of opposites, produces artistic products which appear to embody unconscious material because opposites are equal in the unconscious. O'Neill, for example, was not aware that he was very likely unearthing his own unconscious sexual and aggressive fantasies in equating sex and death in the iceman symbol, but he was aware of the conflict and opposition between the notion of a sexual coming and the coming of death. Ambiguity, tension, and paradox very frequently are manifest goals in an aesthetic creative act. The iceman symbol was not created by means of the type of primary process symbolization found in dreams. It was created, in part, by a secondary process mechanism which allowed unconscious material to appear in consciousness but did not overcome repression. The ego defense which allows such a phenomenon to occur, the defense associated with Janusian thinking, is negation. Freud long ago pointed out that the process of saying something was not so could be an effective means of sidestepping repression without overcoming it.20 Thinking of the opposite, the least likely alternate, simultaneously, is a way of utilizing negation as a defense. In the example of O'Neill's iceman symbol, again, the negation defense operates as follows: sex overtly negates death and vice versa but the simultaneous negation could indicate and indirectly express O'Neill's repressed castration fear. As I have pointed out in some detail elsewhere, ${ }^{4}$ creative artists use the negation defense in other aspects of the creative act beside the Janusian process and defensive negation may very well be one of the hallmarks of creativity. 


\section{Janusian Thinking in the Creative Process}

There is reason to believe that Janusian thinking operates widely in diverse types of creative processes. In Eastern culture, the concepts of Yin and Yang, Mazda and Ahriman, Nirvana and Samsara, are creations of the mind of man which convey simultaneous oppositions. In Western culture, pre-Socratic conceptions of Being and Becoming, religious conceptions of God and the Devil, Nietzsche's formulation of Dionysian and Apollonian, Freud's concept of the id containing a sexual and aggressive instinct or the Eros and Thanatos idea, all convey an integration of opposites. These concepts, like the iceman metaphor, are final products of creative thought and their mere existence does not prove that Janusian thinking, a relatively early phenomenon in the creative process, accounted for their formulation. As mentioned before, however, there is evidence that O'Neill's original idea for The Iceman Cometh play was based on a simultaneous conception of opposites and we can infer that the oppositional iceman symbol, a later formulation related to the original idea, also resulted from such a process. Concepts such as Yin and Yang may have been formulated all at once and only later developed into a metaphysical system on the basis of exegesis of the implications of the metaphor.

In literary creation, the fact that paradox or opposition plays a role in the construction and aesthetic appeal of various types of literature seems to have been recognized for some time. Aristotle was probably the first thinker to emphasize the role of paradox or reversal in tragedy particularly. ${ }^{21}$ Modern critics such as Alan Tate, I. A. Richards, and, more recently, R. P. Warren (unpublished observations) have implicitly and explicitly indicated the importance of opposition in all of fiction. Cleanth Brooks ${ }^{22}$ has at- tempted to support a strong assertion that the basic feature of all of poetry is paradox. Even more pertinent to the issue of simultaneous opposition in the Janusian process, Monroe Beardsley, ${ }^{23}$ the noted aesthetician, has expounded a detailed theory that all metaphor is based on verbal opposition. Metaphor is a very specific and crucial entity in all forms of literature and many have considered the creation of metaphor to be the paradigm for all of literary creation. Furthermore, a metaphor is a unity referring simultaneously to disparate aspects of experience. If Beardsley is right and metaphor is based specifically on verbal opposition, Janusian thinking would clearly play a large role in the creation of metaphor. The importance of metaphor and the general importance of opposition in all of literature suggests that Janusian thinking plays a crucial role in the entire process of literary creation.

In aesthetic fields other than literature, integrated opposition and, by implication, Janusian thinking can be seen to have an important role. In architecture, the Janus metaphor is particularly appropriate since it is necessary for the creative architect to conceptualize the inside and outside of a building simultaneously. For example, convex outer shapes produce concave inner shapes and the architect must reconcile these contradictory spatial characteristics with the overall conception of a building to be built. Furthermore, the best buildings do not convey a quality of spaciousness on the outside which is contradicted once one is inside. Since external shapes conveying spaciousness often deceptively require a great deal of internal buttressing structure and consequent cramping, it is necessary for the creative architect to overcome this. He does this, I believe, by formulating designs which accomplish spaciousness in opposite spatial orientations simultaneously. Frank Lloyd Wright, the great creative ar- chitect, has described the operation of Janusian thinking on an even wider scale than this in his description of the development of Organic Architecture, the type of architecture he created. He referred to the Organic Architecture idea as an "affirmative negation,"24 meaning that it negated the three-dimensional concept in architecture and affirmed it simultaneously. In the visual arts, the capacity to attend to the ground (in Gestalt terms) without loss of figure perception and the painter's freedom to reverse figure and ground to a degree that is not characteristic of ordinary perception seems to represent an ability to maintain opposite orientations simultaneously. The visual effect of moving back and forth while standing still, which has been achieved by artists of the "Op" school, is an example of an art product which may have involved Janusian thinking at some stage.

An interesting example of Janusian thinking in music comes from Arnold Schoenberg's creation of the twelve-tone scale, an important development leading to the so-called atonal movement in modern music. Schoenberg reported that he had arrived at a notion that consonance and dissonance were equivalent. "Dissonances are only the remote consonances,"25 he said-a highly revolutionary integration of opposites.

Scientific and mathematical creators also seem to use Janusian thought. Poincare, the great and clearly creative mathematician, referred explicitly to a process of combining elements "drawn from domains which are far apart" and "as disparate as possible" in his discoveries. ${ }^{26}$ The recent discovery of the "double helix" structure of DNA, the basic factor in genetic replication, shows a dramatic example of the operation of Janusian thinking in creative scientific thought. The double helix structure discovered by Watson contains two similar but opposed spatial forms. 
In his fascinating book describing the discovery of this structure, Dr. Watson makes clear that the notion of identical chains running in opposite directions occurred to him all at once. After describing a long period of struggle consisting of numerous observations by $x$-ray crystallography combined with careful logical assessment of alternate possibilities, Watson indicates that the actual discovery occurred as follows:

When I got to our still empty office the following morning, I quickly cleared away the papers from my desk top so that $I$ would have a large flat surface on which to form pairs of bases held together by hydrogen bonds. Though I initially went back to my like-with-like prejudices, I saw all too well that they led nowhere. When Jerry Donohue came in I looked up, saw that it was not Francis [Crick], and began shifting the bases in and out of various other pairing possibilities. Suddenly I became aware that an adenine-thymine pair held together by two hydrogen bonds was identical in shape to a guanine-cytosine pair held together by at least two hydrogen bonds. All the hydrogen bonds seemed to form naturally; no fudging was required to make the two types of base pairs identical in shape. . . .

The hydrogen bonding requirement meant that adenine would always pair with thymine, while quanine could pair only with cytosine. Chargaff's rules [adenine equals thymine, guanine equals cytosine] then suddenly stood out as a consequence of a double-helical structure for DNA. Even more exciting, this type of double helix suggested a replication scheme much more satisfactory than my briefly considered like-with-like pairing. Always pairing adenine with thymine and guanine with cytosine meant that the base sequences of the two intertwined chains were complementary to each other. Given the base sequence of one chain, that of its partner was automatically determined. Conceptually, it was thus very easy to visualize how a single chain could be the template for the synthesis of a chain with the complementary sequence.

Upon his arrival Francis did not get more than halfway through the door before I let loose that the answer to everything was in our hands. Though as a matter of principle he maintained skepticism for a few moments, the similarly shaped A-T and G-C pairs had their expected impact. His quickly pushing the bases together in a number of different ways did not reveal any other way to satisfy Chargaff's rules. A few minutes later he spotted the fact that the two glycosidic bonds (joining base and sugar) of each base pair were systematically related by a dead axis perpendicular to the helical axis. Thus, both pairs could be flipflopped over and still have their glycosidic bonds facing in the same direction. This had the important consequence that a given chain could contain both purines and pyrimidines. At the same time, it strongly suggested that the backbones of the two chains run in opposite directions [italics mine].

The question then became whether the A-T and G-C base pairs would easily fit the backbone configuration devised during the previous two weeks. ... We both knew that we would not be home until a complete model was built in which all the stereo-chemical contacts were satisfactory. There was also the obvious fact that the implications of its existence were far too important to risk crying wolf. Thus I felt slightly queasy when at lunch Francis winged into the Eagle [restaurant] to tell everyone within hearing distance that we had found the secret of life.27

Watson's description makes clear that the actual breakthrough consisted of conceiving simultaneously of identical but spatially opposed forms. Also, he indicates that this breakthrough was not the complete answer, not the total creation, so to speak, but that a whole system of reactions had to be worked out to give it coherence and validity.

A relatively recent and influential creation in the realm of social thought is the work of Marshall McLuhan. Here, McLuhan's early and central idea is a clear representation of Janusian thinking. ${ }^{28}$ In the development of his theory about the modern ethos based on technological communication, McLuhan initially formulated the idea, "the medium is the message." The sentence meaning and syntax turns back on itself in simultaneous opposition. Preserving the form of a previously held general belief and assumption about messages, ie, "the content is the message," McLuhan substituted the word which was the antithesis of "content" in this context, "medium." In doing so, he has it both ways: he conveys a sense of content to the medium. Although some may question whether McLuhan has actually developed a new or creative philosophical system or whether he has actually applied notions developed by previous thinkers about the relationship of form and content to a new context, there is little doubt that the phrase itself was new at the time it was formulated and that it did spark a relatively new approach to art and modern experience.

\section{Recent Evidence}

Clinical Evidence.-Later, I will discuss some of the reasons that McLuhan's sentence and similar formulations are experienced as creations. Now, I will briefly specify some further evidence for Janusian thinking as a process in creation which has come out of clinical and experimental studies currently in progress. For the past seven years, I have conducted intensive interview studies of prominent and novice creative writers, studies which focus on the writing process itself. These interviews are carried out on a regular weekly or biweekly basis over extended periods of time, from months to several years in some cases, but they focus on the literary work in progress and are not contracted to be therapeutically oriented or to be personality explorations per se. Although I can not reveal the identity of the subjects, the prominent writers have been poets and novelists who have been winners of Pulitzer Prizes, National Book Awards, Bollingen Poetry Prizes, and members of the American Academy of Arts and Letters. Novice writers have been persons of 
varying ages who are serious about a writing career and who have been identified as talented by prominent literary critics and teachers. In addition to these criteria, subjects in both these groups are consistently rated as highly creative by their writer peers. In order to establish a comparison baseline for the results of these interview studies with creative writers, I have also conducted similar intensive interviews with "noncreative" persons engaging in an attempt to produce a work of fiction or poetry for financial reimbursement. These noncreative persons are similar to both the prominent and novice writer subjects in age, sex, socioeconomic characteristics, and ethnic background, but differ in that they have never been interested in literature, have never engaged in serious creative writing on their own, and are not considered creative or creatively oriented by peers or superiors. To be specific, they have not shown evidence or inclination for literary creativity.

During these interview series, I have seen many examples of the process of Janusian thinking in operation in the prominent and novice writer subjects but never in the noncreative persons. In order to indicate the nature of the evidence $I$ have collected and to clarify the specific operation of Janusian thinking in the literary creative process, I will cite some specific examples.

In the course of discussing the circumstances surrounding the genesis of a particular poem, a poet subject told me that he got an idea for a particular poem while walking on a beach. He came upon some rocks and thought that they were heavy and were weapons but that, at the same time, they felt like human skin. The poetic ideas that followed this inspiration and the final poem itself were a comment on the relationship between sex and violence in the world. Indeed, the idea that sex and violence had many things in common was an early realization in this poet's mind as he wrote the poem.

In another instance, a poet was cooking cream of celery soup and began to think of arguments she had heard as child at school that things had no form unless they had boundaries or were in a container. She thought of the fact that cream of celery soup had no form outside the pot and simultaneously thought of the first line of a poem which went as follows: "Cream of celery soup has a soul of its own." In this case, using the term "soul", she was thinking of an entity which was both formed and formless. The total poem went on to become a vibrant statement of conflict between herself as a child and as an adult.

The two examples cited indicate the way in which Janusian thinking enters into the formation of poetic content. A third example relates to the operation of Janusian thinking in relation to alliteration, a formal property (not, of course, divorced from content) of the poem. A poet with a Southern background created a line, the best in the poem he felt, which contained the words "price" and "praise" in an alliterative sequence. Spontaneously, the poet informed me that he had thought of these words together and, in the South, they would be pronounced almost identically. After some questioning, the poet readily acknowledged that, in the context of the poem, the words "price" and "praise" denoted oppositions, referring to paying a price, a punishment, and being praised, a reward.

In numerous instances throughout these interviews, single phrases, images, and metaphors which were embodiments of simultaneous opposition were the starting points for poems. Because of the necessity of preserving the anonymity of my subjects I cannot quote actual poems or significant lines and the examples I have given necessarily lack some richness. Richer examples taken from final versions of poems by poets $I$ have not worked with are
Hart Crane's "penniless rich palms,"29 Keat's "all his men looked at each with a wild surmise/Silent upon a peak in Darien,"30 Hopkins' "all life death does end"31 and "Elected silence, sing to me,"32 as well as Emerson's ${ }^{33}$ section from the poem, "Brahma":

Far or forget to me is near

Shadow and sunlight are the same

The vanished gods to me appear

And one to me is shame and fame.

This is an explicit series of poetic statements embodying Janusian thought.

Novels also, in their early stages, have been powered by Janusian thinking. In one instance, a revolutionary hero was conceived as being responsible for the deaths of hundreds of people but only killing one person with his own hand; this person was someone who was kind to him and whom he loved. This idea occurred early during the germination of the plot and much of the subsequent novel became an elaboration of it.

The examples cited pertain to concrete manifestations of form or content that demonstrate Janusian thought. I would like to make clear, however, that such thinking can operate to dictate formal aspects of cognition as well as to account for actual words and contents. The artist's capacity to integrate abstract ideas with concrete forms, a capacity which Arnheim ${ }^{34}$ suggests is the hallmark of aesthetic creation, can be considered to be a capacity to maintain opposite cognitive orientations simultaneously. The notion of "regression in the service of the ego" connotes a cognitive orientation in which past and future are manipulated simultaneously and, indeed, my subjects consistently show me as we explore the experiential roots of their work that their literary themes come out of their past and are concomitant projections into the future.

Experimental Evidence.-In addition to the clinical evidence for the existence of Janusian thinking 
in creation, preliminary results of some experiments I have carried out tend to confirm the hypothesis. In one experiment (Rothenberg, unpublished data), carried out in similar fashion to the study by Carroll et $\mathrm{al}^{35}$ on opposite responding to the Kent-Rosanoff (K-R) word-association test, a high tendency to rapid opposite responding was found in a creatively oriented group of male college students. The standard K-R word-association test procedure (including measurement of response time) was administered to a population of 114 male college students. On the basis of a detailed questionnaire designed to assess creative orientation and performance in the arts and in science, the subjects were divided into two groups: high creative orientation and low creative orientation. Proportion of opposite responses to the $K-R$ stimulus words (eg, "white" as a response to stimulus word "black", "health" as a response to stimulus word "sickness") and the mean difference of time response between these opposite responses and all other responses were computed for both groups. Analysis of results indicates that the high group gave a significantly greater proportion of opposite and contrast responses in a significantly shorter period of time (latency of response) than the low group. The results of the experiment by Carroll et al had previously indicated that certain groups of subjects responded to the K-R test preferentially with opposite and contrast words, but that experiment had not identified such subjects as potentially creative (no identification of salient subject characteristics was made; also, response times were not recorded). Although associating in opposites to the K-R test is not equivalent to directed or creative thinking, the results suggest a proclivity toward verbal opposition in persons with a high creative orientation. Furthermore, the rapidity of opposite responding in the high creative orientation group suggests that opposite associations could occur simultaneously in creative work.

Other experimental procedures have been carried out to clarify and test hypotheses about opposite and contrast word associations versus word associations which are merely different (Rothenberg, unpublished data). Again, rapid opposite and contrast associations rather than merely different ones were characteristic of aesthetic and creative groups. Special association tasks as well as the K-R word-association test have also been administered to prominent and novice creative writers, the subjects of the interview studies described above. Preliminary assessment of the results of these latter studies indicates a high propensity to rapid oppositional association in these highly creative subjects as well. Further studies assessing the role of Janusian thinking as a function of directed thought as well as a function of associative processes are in progress.

\section{Janusian Thinking, Dialectical Thinking, Conflict, and Ambivalence}

Before going into the specific relationship between Janusian thinking and creation, it is necessary to clarify the critical distinctions between Janusian thinking and other processes which may or may not be related-dialectical thinking, conflict, and ambivalence. Superficially, Janusian thinking might seem to bear a resemblance to dialectical thinking, an important and productive mode of thought having definite metaphysical roots, especially as defined by Hegel.36 Janusian thinking is, however, clearly distinct from dialectical thinking with respect to the temporal attributes of simultaneity and sequence. Both Janusian thinking and dialectical thinking involve opposition but Janusian thinking requires simultaneity of opposition, whereas dialectical thinking involves consideration of opposites, contrasts, and contradictions in sequence. The Hegelian dialectic starts with an assertion of a thesis followed by a counterthesis which is then followed by resolution of the opposition through synthesis. Although actual dialectical thinking may not follow such a clear stepwise sequence in the mind of the person conceiving the dialectic prior to his expounding it or setting it down on paper, it basically involves a weighing of contradictory alternatives, a process which inevitably requires sequential steps rather than simultaneity. To be sure, when one tries to unravel the truth of a Janusian thought according to logical criteria, one may then engage in a dialectical process, but the Janusian thought itself is not the result of this particular process. For example, after O'Neill conceived of the iceman symbol with its simultaneous opposition between sex, death, and Christ's coming, he may have reflected on the implications of the equation of opposites and the synthesis, ie, death's coming is a deliverance from a suffering life; Christ's coming is a deliverance from suffering and death, etc.

Conflict is intrinsic to the opposition in a Janusian thought. One of the particular values of Janusian thinking in art is that it produces both cognitive and affective conflict in an observer, creating suspense and surprise and acting as a stimulant to thought. Furthermore, as I have suggested in the earlier discussion of negation, the particular content of a Janusian thought is very likely highly related to conscious and unconscious emotional conflicts in the creator himself. Janusian thoughts are not simply manifestations of emotional conflicts alone, however, nor do they function solely to instill conflicts in others. Janusian thoughts resolve aesthetic as well as scientific problems. They provide integrations and harmonies in art and theoretical and practical solutions in science. The simultaneous presence of contradictory and 
conflictual elements in the creator's consciousness allows for new integrations and resolutions and the Janusian thought must be susceptible to such resolutions to be more than a logical absurdity. Mrs. Malaprop's memorable statement in The Rivals, 37 "we will not anticipate the past-so mind, young people-our retrospection will be all to the future," is humorous but not an artistic creation in itself because the context does not indicate any integration or resolution of the contradictory elements in her statement.

The term, ambivalence, has been used in a variety of ways since Bleuler's original coinage of the word to describe schizophrenic processes. I cannot here go into the relationship between Janusian thinking and schizophrenic thought but will simply discuss ambivalence as Freud used the term, in relation to contradictory feelings. Ambivalence is distinct from Janusian thinking in that the contradictory feelings of ambivalence are not simultaneously present in consciousness. Although we often can conceptualize our own ambivalence and indicate that we have mixed feelings about someone or something, we do not consciously experience contradictory feelings simultaneously. We do not, for example, experience feelings of love and hate simultaneously, but we may feel them in an alternating sequence. When we observe that someone appears ambivalent about something or someone, we are making an inference from his behavior-he is conscious only of feeling positive or negative at a given moment. I do think that ambivalence, like emotional conflict, probably has strong links to Janusian thinking and may even be a prior condition for the ability to have Janusian thoughts. Creative people are often highly ambivalent in many aspects of their lives. Ambivalence may be related to Janusian thinking but it is far from a sufficient condition for its appearance.

\section{Janusian Thinking in Creation}

I began this exposition of Janusian thinking by raising the problem of the definition of creations and of creativity and the notion of novelty in that definition. I also suggested that a complete explanation of the act of creation may be intrinsically and logically impossible. I will not withdraw that suggestion at this point but will try to spell out the significance of Janusian thinking in creation. As one of the thought processes employed by creators during the act of creation, Janusian thinking does not contradict the view that the nature of creations may be intrinsically unpredictable and that creation is an undetermined event.

In a strictly deterministic view of the universe, there is nothing truly new under the sun or suns. Not only have all thoughts and productions (particularly human thoughts and productions) been anticipated in the thoughts and productions of the past, but all apparently new events are simply recombinations of factors previously in existence. According to this view, newness or novelty is basically a phenomenon experienced in the eye of the beholder and the creation of the world is simply an unknown event, not an unknowable one. Leaving aside, for the moment, the possible fallacious metaphysical implications of such a position, let me say that Janusian thinking goes a long way toward explaining the appearance of creations in this extreme determinist context. In its purest form, Janusian thinking consists of conceiving a notion, belief, or "fact" which is generally taken to be absolutely true and formulating its opposite or contradiction simultaneously. An example of such a pure Janusian thought which has so far not led to a creation (as far as I know) is, "The sun will rise tomorrow" simultaneously accompanied by "The sun will not rise tomorrow." The product of such a thought, an integration of these contradictory ideas, would be experienced as new in the eye of a beholder because no one had ever before considered the possibility that the sun could both rise and not rise tomorrow. So, too, any time that an opposite or contradiction is posited as of equal value or truth as a previously held notion, belief, or fact, it would be experienced as new and, by the laws of chance, occasionally of value. In art, such equating of opposites could account for a good deal of the sense of surprise and novelty which is intrinsic to artistic creations. If scientific creations are simply important and valuable discoveries which are surprising and appear novel in the eye of a beholder, the integration of opposition and contradiction can explain a good deal of scientific creation as well.

I think it is incorrect to espouse this extreme determinist view although it would clearly give Janusian thinking a very critical role in creation. Nevertheless, I think it is untenable to assert that creation exists only in the eye of the beholder and that nothing is truly new. There are many events which have been truly radical departures from anything preceding and are in no sense contradictions of the past, even integrated contradictions. (The notion of truth of any kind existing only in the eye of the beholder also raises the whole Idealism-Realism philosophical controversy. The position of Idealism has been rejected by modern philosophy many times over and the determinist argument cited is rendered further untenable by its implying such a position.) The creation of the universe and of life are models for such radical creation and human creations have often followed such models in kind if not in degree. I will not pursue this argument further here because I think it is self-evident that neither strict determinism nor Janusian thinking by itself is up to explaining such events as Shakespeare's Hamlet, Beethoven's 
Ninth Symphony, or Einstein's Theory of Relativity. The determinist position can simply account for one of the effects of Janusian thinking as a factor in the creative process.

Janusian thinking is a factor in the creative process but it must be accompanied by many other cognitive, affective, and synthetic processes before an actual creation is produced. Opposition is a complicated phenomenon and it can often be so idiosyncratic that it has no communicative value and, hence, no value in artistic type of creation and probably other types as well. There is a wide variety of types of opposition, ranging from strong opposition containing logical antithesis or contradiction to mild opposition consisting of simple contrast. To return to the Janus metaphor, the god simply faces in two distinct directions simultaneously. When the Janusian thought embodies strong opposition or logical antithesis it has the greatest shock or surprise value; it conveys the greatest sense of novelty and may also convey the greatest truths. In artistic creation, for example, many integrations of opposites do not convey this sense of surprise and novelty because they are integrations of contrasts rather than contradictions. Most metaphors are really manifestations of the integration of mild oppositions or contrasts. Although Beardsley's verbal opposition theory of metaphor, referred to previously, is basically sound, he does not take this multilevel nature of opposition adequately into account in his analysis.

Actually, when taken literally, the conception of true opposite depends a good deal on the level of sophistication of the conceiver. For example, many people take red and green or blue and yellow to be opposites. In certain contexts, say in the use of a palette, this may be true but in terms of the physical spectrum, red and blue are actually polar extremes and, therefore, opposites. Given these limitations and variations, how then does opposition actually function in creative thought?

I think it functions specifically in relation to sophistication and other factors which allow the creator to know and sense the most salient oppositions in the human and physical world at a particular point in time or, sometimes, throughout human history. The truly creative person knows his field well and also knows which widely held notions, beliefs, and "facts" are important and susceptible to opposition or contradiction on some level. It is this type of knowledge, a knowledge which may come into play after the creator hits on an integrated opposition by chance, unconscious determination, or other factors, which makes the Janusian thought meaningful and, in fact, valuable. Many oppositions, or disparate elements, as Poincare stated in another part of the same statement cited earlier, are useless and without any value whatsoever. ${ }^{26}$

With respect to value, I have said little of the many other processes including psychological dynamisms which actually integrate oppositions as well as capacities and facilities with words, plastic materials, and conceptual symbols. These and myriad other factors go into the creative process and have a good deal to do with imparting value to a created product, but they cannot be elaborated here. Moreover, I do not intend to claim that Janusian thinking is the only or even the primary type of process accounting for inspirations or creative ideas, as I think I have made clear. Many of the other factors are so far not only unknowable. Janusian thinking is, and, as I have suggested, possibly unknowable. Janusion thinking is, however, a factor in the creative process and it is the first specific thought process in creativity to be defined.

This study was supported by Public Health Service Research Scientist Career Program Award No. 23,621 from the National Institute of Mental Health.

\section{References}

1. Lombroso C: The Man of Genius. London, Walter Scott Ltd, 1895.

2. Galton F: Hereditary Genius. New York, D Appleton \& Co, 1870.

3. Freud S: Dostoevsky and parricide (1928), in Strachey J (trans-ed) : Complete Psychological Works, standard edition. London, Hogarth Press

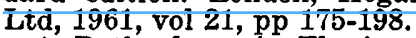

4. Rothenberg A: The iceman changeth: Toward an empiricai approach to creativity. J Amer Psychoanal Assoc $17: 549-60 \overline{7}, 1969$.

5. Rank 0: Art and Artist. New

York, Alfred A Knopf Inc, 1932.

6. Lee HB: A theory concerning free creation in the inventive arts. Psychiatry $3: 229-293,1940$.

7. Greenacre P: The childhood of the artist. Psychoanal Study Child $14: 61-80,1957$.

8. Rose G: Creative imagination in terms of ego "core" and boundaries. Int J Psychoanal 45:75-84, 1964.

9. Rosen V: Effects of talent on character style. Psychoanal Quart $33: 1-24,1964$.

10. Kris E: Psychoanalytic Explorations in Art. New York, International Universities Press Inc, 1952.

11. Guilford JP, Wilson RC, Christenson PR: A Factor Analytic Study of Creative Thinking: II. Administration of Test and Analysis of Results. University of Southern California Psychology Laboratory Report No. 8, 1952.

12. MacKinnon DW: The study of creative persons, in Kagan $J$ (ed): Creativity and Learning. Boston, Beacon Press Inc, 1967.

13. Mednick SA, Mednick MT: An associative interpretation of the creative process, in Taylor CW (ed) : Widening Horizons in Creativity. New York, John Wiley \& Sons Inc, 1964.

14. Parnes SJ: Research on developing creative behavior, in Taylor $\mathrm{CW}$ (ed): Widening Horizons in Creativity. New York, John Wiley \& Sons Inc, 1964

15. Erikson EH: Young Man Luther: A Study in Psychoanalysis. New York, WW Norton \& Co Inc Publishers, 1958, p 100.

16. Hausman CR: The role of form, value, and novelty in creativity, in Vaught C (ed): Essays in Metaphysics. University Park, Pa, Pennsylvania State University Press, to be published.

17. Morgan L: The Emergence of Novelty. London, Williams \& Norgate Ltd, 1933.

18. Jung CG: The psychology of the unconscious in Hull FC (trans): Two Essays on Analytical Psychology. New York, Pantheon Books Inc, 1953. 
19. Kris E: Spontaneous artistic creations by psychotics, in Kris $\mathbf{E}$ : Psychoanalytic Explorations in Art. New York, International Universities Press, Inc, 1952, p 116.

20. Freud S: Negation (1925), in Strachey J (trans-ed): Complete Psychological Works. London, Hogarth Press Ltd, 1961, vol 19, pp 235-242.

21. Aristotle: Poetics. SH Butcher (trans), New York, Macmillan Co Publishers, 1911.

22. Brooks C: The language of paradox, in Tate $A$ (ed): The Language of Poetry. Princeton, NJ, Princeton University Press, 1942.

23. Beardsley M: The metaphorical twist. Philosophy Phenomenological Res 22 :293-307, 1962.

24. Wright FL: Organic architecture looks at modern architecture, in

Puma F (ed) : Seven Arts. New York, Doubleday \& Co Inc, 1953.

25. Schoenberg A: Style and Idea. New York, Philosophical Library Inc, $1950, \mathrm{p} 104$

26. Poincaré $\mathrm{H}$ : Mathematical creation, in Ghiselin B (ed): The Creative

Process: A Symposium. New York, New American Library Inc, 1955.

27. Watson J: The Double Helix.

New York, New American Library Inc, 1968.

28. McLuhan M: Understanding Media: The Extensions of Man. New York, McGraw-Hill Book Co Inc, 1964. 29. Crane H: "Voyages II," in Weber B (ed): The Complete Poems and Selected Letters and Prose of Hart Crane. Garden City, NY Doubleday \& Co, Inc, 1966

30. Keats J: “On First Looking Into Chapman's Homer," in Thorpe CD (ed): John Keats: Complete Poems and Selected Letters. New York, Odyssey Press Inc, 1935.

31. Hopkins GM: "No Worst There is None. Pitched Past Pitch of Grief," in Williams O. (ed): A Little Treasury of Modern Poetry. New York, Charles Seribner's Sons, 1947.

32. Hopkins GM : "The Habit of Perfection," in Williams $O$ (ed): $A$ Little Treasury of Great Poetry. New

York, Charles Seribner's Sons, 1947.

33. Emerson RW: "Brahma," in Williams $O$ (ed):A Little Treasury of Great Poetry. New York, Charles Scribner's Sons, 1947.

34. Arnheim R: Psychological notes on the poetical process, in Arnheim R, et al (eds) : Poets at Work. New York, Harcourt Brace \& World Ine, 1948.

35. Carroll JB, Kjeldegaard PM,

Carton AS: Number of opposites versus number of primaries as a response measure in free astociation test. Verbal Learning Verbal Behav 1:22$30,1962$.

36. Hegel GWF: The science of logic, in The Encyclopedia of the Philosophical Sciences. W Wallace (trans), London, Oxford University Press, 1965.

37. Sheridan RB: The rivals, in Moore CA (ed) : Twelve Famous Plays of the Restoration and Eighteenth Century. New York, Random House Inc, 1933, p 849 . 